\title{
A CIDADANIA DE CRIANÇAS E ADOLESCENTES \\ NO BRASIL: CAMINHOS E DESAFIOS
}

\author{
Danilo José Viturino Soares ${ }^{1}$
}

\section{RESUMO}

O artigo em tela tem por objetivo realizar uma análise sobre o surgimento e desenvolvimento da cidadania de crianças e adolescentes no Brasil. Através de referenciais teóricos clássicos do pensamento político brasileiro e de abordagens de curto-alcance, buscamos entender o complexo processo de garantia de direitos, e mudanças de paradigmas no que se refere a estes sujeitos. Apesar de grandes avanços com a implementação do Estatuto da Criança e do Adolescente e todo seu aparato burocrático-administrativo, as heranças da velha política social menorista, de manutenção das desigualdades socioeconômicas, persistem simultaneamente com a concepção de uma infância universal. Longe de apresentar uma saída para tal dualidade, este artigo serve de aporte teórico para novas reflexões.

Palavras-chave: Cidadania; Infância Universal; Criança e Adolescente; Código de Menores.

\section{ABSTRACT}

The article on screen aims to carry out an analysis on the emergence and development of citizenship of children and adolescents in Brazil. Through wellknown theoretical references of Brazilian political thinking and short-range approaches, we seek to understand the complex process of guaranteeing rights, social representations and paradigm shifts with respect to these subjects. Despite great advances in the implementation of the Child and Adolescent Statute and all its bureaucratic-administrative apparatus, the legacies of the old minorist social policy, of maintaining socioeconomic inequalities, persist simultaneously with the conception of a universal childhood. Far from presenting an outlet for such duality, given its extreme complexity, this article serves as a theoretical contribution to new reflections.

Keywords: Citizenship; Universal Childhood; Child and teenager; Code of Minors

${ }_{1}^{1}$ Mestrando em Ciências Sociais pelo Programa de Pós Graduação em Ciências Sociais da Universidade Federal de Juiz de Fora - PPGCSO/UFJF. Contato: Danilo.viturino@gmail.com 
O fenômeno da cidadania é complexo. Trabalhar em meio a sua polifonia torna-se um desafio na definição do estado da arte. Buscamos refletir, a partir de alguns aportes teóricos, o problema da cidadania e seus significados com ênfase na cidadania de crianças e adolescentes no Brasil ${ }^{2}$. Para isso, valemo-nos de reflexões cristalizadas no campo do pensamento social brasileiro, bem como a utilização de teorias de curto alcance que tratam especificamente de refletir sobre esta fração social, suas representações, seus aspectos históricos, bem como também a formulação de políticas públicas para sua intervenção e controle.

Delimitamo-nos a entender a cidadania como um fenômeno histórico, cujo embrião encontra-se na formação da sociedade moderna ocidental, marcada pela centralidade no indivíduo, nos ideais de liberdade e igualdade e sua relação com o Estado moderno, em nosso caso, periférico. Ao realizar tão recorte teórico, mobilizamos alguns intelectuais que, apesar de suas dicotomias analíticas e conceituais, pautam basicamente suas análises sobre Brasil neste terreno, como por exemplo, Caio Prado Jr., Roberto DaMatta, Wanderley Guilherme dos Santos, Jessé de Souza e José Murilo de Carvalho; paralelo a autores e autoras que tratam especificamente da temática da criança e do adolescente no Brasil, como Geralda Luiza de Miranda, Patrice Schuch, Irene Rizzini e Claudinei dos Santos Lima.

Convergindo tais intelectuais, buscamos neste artigo realizar uma análise sobre como a cidadania de crianças e adolescentes converge com o caminho da cidadania brasileira, sua relação com os binômios sociedade-Estado, democraciaautoritarismo e entender quais avanços, desafios e paradoxos se apresentam nestes trajetos. Neste artigo, falar da cidadania de crianças e adolescentes é tratar também, em suma, de seus significados, bem como o trato dado pela sociedade e o Estado aos mesmos.

Num primeiro momento, abordaremos a situação da infância brasileira no período colonial, dando importância particular ao impacto da escravidão do negro no Brasil. Em seguida, abordaremos a Primeira República e o início das intervenções estatais a estes sujeitos. Realizado este caminho, descreveremos a grande importância da dinâmica social brasileira e a implementação da primeira lei federal para a infância - o Código de Menores de 1927 e seu impacto na

${ }^{2} \mathrm{O}$ recorte conceitual criança e adolescente abordado neste artigo não se prende especificamente pela faixa etária destes sujeitos, mas sim pelo seu entendimento histórico do conceito de infância como sendo um período de preparação para a vida adulta, tendo a educação e as instituições educacionais um papel fundamental. (ARIĖS, 1981) 
garantia - ou ausência - da cidadania; apontaremos o surgimento, no Estado Novo, das primeiras instituições governamentais, a nível nacional, voltadas para uma parcela específica de crianças e adolescentes, os assim chamados menores. Após o fim do Estado Novo e a curta experiência democrática pré-regime militar, analisaremos como a reforma do Código de Menores em 1979 manteve o paradigma do revogado código de 1927, bem como a influência da ditadura militar nas políticas públicas para a infância e juventude brasileira.

Após o fim do regime autoritário, surge como marco histórico da cidadania o Estatuto da Criança e do adolescente e suas inovações institucionais, bem como algumas mudanças de concepção da infância brasileira. Por fim, refletiremos como a cidadania destes sujeitos está imbricada num complexo processo de garantia de direitos e políticas públicas que mesclam a tendência autoritária e a aspiração democrática, desdobrando-se num paradigma de difícil superação. Além disso, a dinâmica econômica e internacional que o país está engendrado nos coloca ante um desafio de programar uma agenda social num modelo capitalista neoliberal.

A cidadania de crianças e adolescentes no Brasil tem sua gênese nas legislações específicas para a infância e juventude. Ocorre no século XIX, apenas como regulação normativa de específica parcela infanto-juvenil. A primeira lei sancionada foi na Primeira República, o Código de Menores de 1927³. A segunda foi o Código de Menores de $1979^{4}$ que manteve muitas estruturas ligadas ao seu antecessor. Com a redemocratização do país e a promulgação da Constituição Federal de 1988, é sancionada a Lei 8069/90, o Estatuto da Criança e do Adolescente - ECA em que crianças e adolescentes deixam de ser menores sujeitos de intervenção por sua condição de delinquência, passando a sujeitos de direitos, em situação peculiar de desenvolvimento, sob a proteção integral do Estado, da sociedade e da família.

Noperíodo imperial as políticas sociais não estavam delimitadas na Constituição de 1824; as elites dominantes tinham como objetivo colocar o Brasil no patamar das sociedades modernas ocidentais - logo, a Europa e os Estados Unidos - com uma Carta Magna de características liberais progressistas. Além disso, os baixos índices de urbanização e industrialização ainda não tinham colocado esta agenda em discussão:

${ }^{3}$ Decreto No 17.943-A de 12 de outubro de 1927.

${ }^{4}$ Lei Nº 6.697, De 10 de Outubro de 1979. 
O Brasil de 1824, apoiado em uma organização escravista da produção, ao mesmo tempo em que iniciava a construção de um Estado nacional sob a inspiração de discípulos do liberalismo progressista da época, constituiria esdrúxulo exemplo de desvio ideológico e organizacional, caso estruturasse sua vida jurídica em descompasso com o que havia de mais "avançado" à época. Em realidade, ao desconhecer a existência de um problema social, por um lado, e ao recusar-se a regular profissões, abolindo as remanescentes corporações coloniais de ofício, por outro, a constituição de 1824 acertava seu passo com a modernidade de início do século XIX. (SANTOS, 1979, p. 18)

Na Primeira República, a sindicalização dos trabalhadores urbanos deu início a luta por melhorias nas condições de trabalho e, por consequência, no interesse dos mesmos em colocar na agenda os problemas decorrentes da urbanização e dos direitos trabalhistas. A tímida, mas crescente industrialização colocou em pauta a regulamentação do trabalho noturno de meninos e meninas em fábricas, como afirma Wanderley Guilherme dos Santos:

É só em 1890, pelo Decreto 439, de 31 de maio, que o poder público no Brasil, e ainda replicando os estágios das intenções de todas as elites incumbidas de administrar a acumulação mercantil-industrial, manifesta preocupação pelo uso da força de trabalho infantil, enunciando as bases da assistência à infância desvalida. [...] Logo a seguir, o decreto 1313 do Governo Provisório, de 17 de janeiro de 1891, regulamenta o trabalho dos menores nas fábricas da Capital Federal, decreto que, para surpresa dos fetichistas da lei, jamais foi cumprido. (SANTOS, 1979, p. 20)

É na lógica do mundo produtivo que a cidadania toma forma no Brasil, através da garantia primeira dos direitos sociais, somente depois os direitos políticos e civis (CARVALHO, 2008). Para criar a força de trabalho que o país necessitava, forja-se na primeira República o esboço da intenção do Estado brasileiro em alfabetizar e regulamentar o trabalho infantil, elaborando-se projetos de leis que obrigavam o empregador a garantir o direito à educação dos pequenos proletários analfabetos. Mas ainda assim, ficou apenas na intenção. A política do laissez-faire repressivo constrangia a arena política no que tange os direitos sociais perseguindo os sindicatos e, no bojo das garantias trabalhistas, os primeiros direitos específicos para crianças e adolescentes no Brasil tiveram 
pouquíssima efetividade. (SANTOS, 1979)

No cenário internacional, surgiram organizações voltadas para o bem estar da criança, como a Children's Bureal (Estados Unidos, 1912), a Associação Internacional para a Proteção da Infância (1913) e o Instituto Interamericano Del Niño (sede em Montevidéu, 1917). Contudo, ainda não existia consenso nos discurso entre essas e outras organizações internacionais. Assim, em 1924 a Liga das Nações aprova a Declaração de Genebra, com o crivo decisivo dos Estados Unidos ao afirmar a necessidade de proteção das crianças, mas não deixava claro quem seria responsável por tal proteção. Surge neste momento a gênese do conceito de infância universal, que posteriormente, com a Declaração dos Direitos da Criança em 1959, foi concebida como:

[...] um período de vida dotado de universalidade, cujos seres assim percebidos eram definidos como em estado de desenvo/vimento. Essa classificação instaura um paradoxo: ao mesmo tempo em que a criança e o adolescente são definidos como portadores de direitos, tal definição firma uma situação de excepcionalidade, reafirmada posteriormente com a promulgação da Convenção Universal dos Direitos da Criança, de 1989, que os definiu como sujeitos de direitos especiais, alvos das políticas de proteção especial. (SCHUCH, 2005, p. 298)

Voltando ao Brasil, entre os anos de 1923 e 1933 surgiram dispositivos jurídicos importantes, destinados a atender demandas dos trabalhadores e além de tudo, resolver os problemas referentes à acumulação e equidade na nova sociedade industrial (SANTOS, 1979). Houve intensos debates entre o final do século XIX e início do século XX em relação a crescente urbanização, insegurança pública, desenvolvimento industrial e delinquência no Rio de Janeiro e São Paulo. Além disso, juristas da época realizaram as primeiras ações alegando a necessidade de modernizare humanizar o direito; bem como médicos sanitaristas alertavam os governos sobre a necessidade de medidas que combatessem os altos índices de mortalidade infantil. (COSTA, 1979; RIZZINI, 1995; SCHUCH, 2005)

Neste breve momento de discussões e propostas de ações, onde diversos atores sociais participaram - como, por exemplo, associações caritativas e filantrópicas, as cruzadas médicas, setores políticos e membros do poder judiciário - em 1924 surge o primeiro Juízo de Menores no Brasil, cuja função contemplava os poderes judiciário e executivo, fazendo da justiça de menores 
uma justiça assistencialista. (SCHUCH, 2005)

Assim, foi sancionado o Código de Menores - Decreto-lei 17.934-A de 12 de outubro de 1927, destinado especificamente a crianças e adolescentes mendigos, abandonados, infratores, andarilhos, etc., sempre denominados menores, que estivessem em situação irregular.

O menor, como categoria de hierarquização social, era o personagem social que abarcava uma ampla gama de substantivos e adjetivos diversos - "crianças desvalidas", "miniaturas facínoras", etc. - atribuídas na prática policial e jurídica àqueles indivíduos definidos legalmente em situação de menoridade. Como uma vasta bibliografia sobre o assunto tem destacado, o "menor" era definido, primordialmente, em torno de sua situação de subordinação social pela pobreza. (SCHUCH, 2005, p. 59)

A situação de subordinação social pela pobreza não era novidade no Brasil, a situação do negro na escravidão iniciou este processo, o qual a carência de preocupação da sociedade e das autoridades públicas deixou ainda mais complexa a situação. A escravidão é uma das instituições que mais afetaram nosso tecido social e o ordenamento político do país. Joaquim Nabuco (2000, p. 3), em seu livro O Abolicionismo, relata que "O nosso caráter, o nosso temperamento, a nossa organização toda, física, intelectual e moral, acha-se terrivelmente afetada pelas influências com que a escravidão passou trezentos anos a permear a sociedade brasileira."

Cuja amálgama é tão profunda que somente a tarefa de abolir a escravidão, ainda segundo o autor, não seria - como não foi - suficiente para romper com seus efeitos mais nefastos:

Quando mesmo a emancipação total fosse decretada amanhã, a liquidação desse regime só daria lugar a uma série infinita de questões, que só poderiam ser resolvidas de acordo com os interesses vitais do país pelo mesmo espírito de justiça e humanidade que dá vida ao abolicionismo. Depois que os últimos escravos houverem sido arrancados ao poder sinistro que representa para a raça negra a maldição da cor, será ainda preciso desbastar, por meio de uma educação viril e séria, a lenta estratificação de trezentos anos de cativeiro, isto é, de despotismo, superstição e ignorância. O processo pelo qual a escravidão fossilizou nos seus moldes a exuberante vitalidade do nosso povo durante 
todo o período de crescimento, e enquanto a nação não tiver consciência de que lhe é indispensável adaptar à liberdade cada um dos aparelhos do seu organismo de que a escravidão se apropriou, a obra desta irá por diante, mesmo quando não haja mais escravos. (NABUCO, 2000, p. 3)

Em associação à grande propriedade, a monocultura e a economia de exportação, a escravidão colocou o negro na marginalidade social, negando-lhe a inserção ao mundo produtivo, aos valores modernos que o país aspirava e ao forjamento da cidadania:

O negro não teve no Brasil a proteção de ninguém. Verdadeiro pária social, nenhum gesto se esboçou em seu favor. E se é certo que os costumes e a própria legislação foram com eles mais benignos na sua brutalidade escravista que em outras colônias americanas, tal não impediu, contudo que o negro fosse aqui tratado com o último dos descasos no que diz respeito à sua formação moral e intelectual, e preparação para a sociedade em que à força, o incluíram. [...] As raças escravizadas e assim incluídas na sociedade colonial, mal preparadas e adaptadas, vão formar nela um corpo estranho e incômodo. (PRADO JR, 1961, p. 274)

Com a Revolução de 1930, o Código de Menores de 1927 reflete uma conjuntura nacional marcada por intensa regulamentação de profissões e ocupações, a qual Wanderley Guilherme define como cidadania regulada:

São cidadãos todos aqueles membros da comunidade que se encontram localizados em qualquer uma das ocupações reconhecidas e definidas em lei. A extensão da cidadania se faz, pois, via regulamentação de novas profissões e/ou ocupações, em primeiro lugar, e mediante ampliação do escopo dos direitos associados a estas profissões, antes que por expansão dos valores inerentes ao conceito de membro da comunidade. A cidadania está embutida na profissão e os direitos do cidadão restringem-se aos direitos do lugar que ocupa no processo produtivo, tal como reconhecido por lei. (SANTOS, 1979, pg. 75)

Continuando, também conceitua a grande parcela da população que não era contemplada pela lei, como os trabalhadores rurais e os urbanos informais: 
[...] seriam pré-cidadãos todos os trabalhadores da área rural, que fazem parte ativa do processo produtivo e, não obstante, desempenham ocupações difusas, para efeito legal; assim como seriam pré-cidadãos os trabalhadores urbanos em igual condição, isto é cujas ocupações não tenham sido reguladas por leis. (SANTOS, 1979, pg. 75).

A não inclusão do negro resultou, com a crescente urbanização do país, neste processo de exclusão social de toda a camada pobre sem regulação profissional. É nesse ideário de cidadania - que por um lado, inclui o indivíduo na comunidade através da regulamentação profissional, e por outro exclui os que escapam da mesma - que são formuladas as políticas públicas para a infância e juventude a partir dos anos 30, exclusivamente para a parcela marginalizada, pré-cidadã nos termos supracitados.

No período do Estado Novo surge o Serviço de Atendimento aos Menores (SAM), subordinado ao Ministério da Justiça. Segundo Liberati:

O SAM tinha como missão amparar, socialmente, os menores abandonados e infratores, centralizando a execução de uma política de atendimento, de caráter corretivo-repressivo-assistencial em todo território nacional. $\mathrm{Na}$ verdade, o SAM foi criado, para cumprir as medidas aplicadas aos infratores pelo Juiz, tornando-se mais uma administradora de instituições do que, de fato, uma política de atendimento ao infrator. (LIBERATI, 2002, p. 49)

Como prática histórica, o SAM, o Juízo de Menores e o Código de Menores são exemplos do controle e vigilância nas mãos do Estado que, segundo Michel Focault, penetra por toda a espessura da sociedade:

Um sistema geral de vigilância-reclusão penetra por toda a espessura da sociedade, tomando formas que vão desde as grandes prisões, construídas a partir do modelo Panopticon, até as sociedades de patronagem e que encontram seus pontos de aplicação não somente nos delinquentes, como também nas crianças abandonadas, órfãos, aprendizes, estudantes, operários, etc. (FOCAULT, 1997, p. 38)

No campo educacional, consolidou-se uma política nacional cujo currículo Clássico-Científico era pautado no modelo de escola dual, uma destinada à elite 
e a outra voltada para a formação da mão de obra para as classes trabalhadoras. (SILVA, 2007)

Como balanço da época, podemos definir o Código de Menores 1927 como uma resposta de modelo autoritário e tardia para os problemas que a modernização do Brasil trouxe à reboque. O crescimento demográfico, a falta de planejamento urbano efetivo, a marginalização dos moradores das periferias e uma política excludente que tratava crianças e adolescentes pobres como problema de polícia revelam o perfil de um Estado autoritário, mantenedor de uma lógica de desumanização que remontava o período da escravidão e de reconhecimento da infância pelo trabalho (NABUCO, 2000; SANTOS, 1979). Apesar de avanços na legislação social entre 1930 e 1945, a participação política e as garantias dos direitos civis eram precárias (CARVALHO, 2008), logo, o próprio Código de Menores não pode ser definido como uma conquista democrática.

No final dos anos 50 e início dos anos 60, período em que o Brasil passa por uma experiência singular de urbanização, após uma série de congressos realizados por instituições civis e pela influência do debate internacional, colocase em pauta a necessidade de reformulação do Código de Menores de 1927, tendo como principais pautas a necessidade de maior participação comunitária na formulação e implementação das políticas públicas e o papel do Estado no que tange a ação do Juízo de Menores e a criação de creches, escolas, parques infantis e um fundo de combate à miséria e subnutrição familiar (SCHUCH, 2005).

Reformado em 1979, durante o regime militar, manteve a mesma estrutura excludente, abandonando todas as discussões que vinham sendo feitas nos âmbitos nacional e internacional sobre a proteção à criança e focando nas abordagens internas ordenadas pela Doutrina de Segurança Nacional. Tais orientações, conhecidas como Política de Bem-Estar do Menor, eram ditadas pelo Instituto Del Niño e pelas orientações da Organização dos Estados Americanos (OEA), principal alicerce ideológico das ditaduras latino americanas daquele período. (SCHUCH, 2005)

Uma das principais características da Política de Bem-Estarfoi a substituição do Serviço de Assistência ao Menor - SAM - pela Fundação Nacional do BemEstar do Menor - FUNABEM - além das fundações de níveis estaduais FEBEM's, que segundo Arantes (2003, p. 12) "[...]tinham como eixo a política da centralização das decisões e das execuções, da segregação dos "menores em situação irregular", do monopólio estatal no trato da questão, e principalmente, dos 'muros contendores'". 
Numa perspectiva mais ampla, este período também foi marcado pelo cerceamento dos direitos políticos e civis, com a proibição do pluripartidarismo e perseguição a autoridades políticas, juízes, lideranças sindicais e de tantos outros movimentos sociais.

A avaliação dos governos militares, sob o ponto de vista da cidadania, tem, assim, que levar em conta a manutenção do direito do voto combinada com o esvaziamento de seu sentido e a expansão dos direitos sociais em momento de restrição de direitos civis e políticos. (CARVALHO, 2008, p. 172-173)

Com a redemocratização do país no final da década de 1980, o fim da Doutrina de Segurança Nacional possibilita a difusão de diversos debates pelo país, colocando na agenda todo o debate realizado internacionalmente desde o final dos anos 60.

No mesmo ano de promulgação do segundo Código de Menores, em 1979, a UNICEF ea Organização Mundial da Saúde proclamamo Ano Internacionalda Criança, organizando diversos seminários e fóruns de debates internacionais, nos quais foi divulgada a noção de crianças no mundo (world's children) e a possibilidade da categoria infância universal ordenar discursos teóricos e políticos em diferentes frentes temáticas nacionais. [...] Novas leis especiais para a infância e juventude são aprovadas no cenário internacional, como as Regras Mínimas das Nações Unidas para Administração da Justiça da Infância e da Juventude - Regras de Beijing (1985) e as Diretrizes das Nações Unidas para a prevenção da Delinquência Juvenil, Diretrizes de Riad (1988). Em 1989, foi adotada a Convenção sobre os direitos da Criança, firmada pela assembleia Geral das Nações Unidas. Tal documento seguiu a tendência do privilégio das liberdades civis da criança, já explícita na Convenção de Genebra (1924) e na Declaração dos Direitos da Criança (1959), tendo uma grande abrangência internacional e normativa. (SCHUCH, 2005, p. 68-69)

Em virtude do contexto supranacional de discussões e convenções e também da reabertura política nacional, surgiram diversas críticas oriundas de diversos setores da sociedade - juízes, militantes de movimentos sociais, intelectuais sobre o caráter repressor e autoritário que a classificação menor e menor em situação irregular gerava nas políticas para a infância e juventude. (COSTA, A., 
1992; FIGUEROA, 1994; MENDEZ, 1991; PASSETI, 1995; RIZZINI E RIZZINI, 2004; VOLPI, 1997; VOLPI E SARAIVA, 1998; SÊDA, 1991).

Assim, em virtude das mobilizações nacionais e internacionais, torna-se dominante no Brasil o Paradigma da Proteção Integral ${ }^{5}$, ainda que tardiamente, recepcionado na Constituição Federal, em seu Artigo 227, regulado pela Lei 8069/90, o Estatuto da Criança e do Adolescente. Hoje, substitui-se o regime do Prudente Arbítrio pelo Estado Democrático de Direito, dando-se início a uma nova configuração do sistema de proteção a crianças e adolescentes brasileiros. Na visão social, rompe-se com o paradigma da criança como objeto da intervenção jurídico-estatal, reconhecendo-a como pessoa em condição peculiar de desenvolvimento.

Na concepção jurídico-político-social, é instituída a doutrina de proteção integral, instrumento de desenvolvimento social voltado para o segmento social mais sensível. Além disso, o Estatuto da Criança e do Adolescente também serve como marco regulatório da constitucionalização dos direitos da criança na Carta de 1988 e da municipalização das políticas sociais, com a descentralização político-administrativa e participação da população através de organizações representativas, na formulação das políticas e controle das ações em todos os níveis. (ASSIS et al., 2010)

No rearranjo institucional dos poderes e suas atribuições, a União tornou-se responsável por elaborar as normas gerais, cabendo as Unidades Federativas legislarem em caráter complementar e ao município legislar suplementarmente sobre questões locais, principalmente a criação da política municipal de atendimento aos direitos da criança e do adolescente, cuja tarefa é estabelecer diretrizes municipais de atendimento aos direitos da criança e do adolescente, a criação do Conselho Municipal dos Direitos da Criança e do Adolescente, do Fundo Municipal dos Direitos da Criança e do Adolescente e do Conselho Tutelar. (COELHO, 1990)

Na articulação entre Poder Público e sociedade, foi criado o Sistema de Garantia de Direitos (SGD), instância de defesa dos direitos de crianças e adolescentes com o objetivo de proporcionar os mecanismos de defesa, promoção e controle social dos direitos humanos dos mesmos. Segundo Assis, o SGD é dividido em

${ }^{5}$ Sobre a proteção integral, o ECA trata, em seu artigo $3^{\circ}$, que crianças e adolescentes gozam de todos os direitos fundamentais inerentes à pessoa humana, sendo assegurados por esta lei por outros meios, todas as oportunidades e facilidades, no intuito de possibilitar o desenvolvimento integral da pessoa humana, em condições de liberdade e dignidade. 
três eixos temáticos:

Da defesa dos direitos humanos: visa empregar ações para proteger os direitos das crianças e dos adolescentes de forma legal, nas hipóteses de ameaça ou violação; Da promoção dos direitos humanos: realiza-se pelo desenvolvimento de políticas de atendimento aos direitos da criança e do adolescente, de forma transversal e intersetorial. Abrange três tipos de políticas públicas: públicas-sociais, de proteção de direitos humanos e de execução de medias socioeducativas [...] Do controle da efetivação dos direitos humanos: recai sobre os órgãos encarregados pela formulação das políticas públicas-sociais, de proteção e socioeducativas, sendo monitorados, de maneira soberana, pela sociedade civil. [Grifo meu] (ASSIS, et al., 2010, p. 47)

Outros avanços também foram importantes no aperfeiçoamento e institucionalização do ECA, como por exemplo, o estabelecimento da Política Nacional de Redução da Morbimortalidade por Acidentes e Violências, do Ministério da Saúde ${ }^{6}$ em 2001, a aprovação do Sistema Nacional de Atendimento Socioeducativo (SINASE) pelo Conselho Nacional dos Direitos da Criança e do Adolescente (CONANDA) em 2005, do Plano Nacional de Promoção, Proteção e Defesa dos Direitos de Crianças e Adolescentes à Convivência Familiar e Comunitária em 2006 e o Plano Nacional de Enfrentamento da Violência Sexual Contra Crianças e Adolescentes, revisto e publicado em 2013². (Assis et al., 2010)

Toda esta mudança estrutural no trato da infância e juventude no Brasil está engendrada no tema da cidadania. A possibilidade de entrada da sociedade civil organizada na arena política para discutir, implementar e fiscalizar políticas públicas veio com o fim da ditadura e o surgimento de diversos movimentos sociais e suas participações nos conselhos de promoção de direitos nos níveis municipais, estaduais e federal, bem como também dos Fóruns e redes. Segundo Albuquerque, o movimento de defesa dos direitos da criança e do adolescente no Brasil - entendido como movimento $D C A \neg-$ possui basicamente três ciclos:

${ }^{6}$ Portaria MS/GM n 737 de 16 de maio de 2012.

${ }^{7}$ Lei no 12.594 , de 18 de janeiro de 2012.

8 Disponível em: https://goo.gl/8GpCGm. Acesso em: 14 de jan.2017 
O primeiro ciclo teve como pico a criação do ECA. Iniciou na década de 1980, quando surgiram e se articularam a Pastoral do Menor da Igreja Católica, o Movimento Nacional dos Meninos e Meninas de Rua (MNMMR), e uma multiplicidade de outras organizações e indivíduos que se engajaram na defesa dos Direitos da Criança e do Adolescente. [...] Esse amplo movimento social se tornou e articulou aos debates internacionais, avaliou e denunciou a situação nacional, e elaborou propostas para a Constituição Federal, e foram construídas articulações e alianças com atores estatais. [...] O segundo ciclo envolve as lutas pela adequação da política socioeducativa ao ECA e pela extinção das FEBEMS. [...] O movimento envolveu-se, ainda, articulado com outros autores societais e estatais, na construção de novas bases nacionais para uma política socioeducativa, que resultaram na legislação recente que regulamenta o Sistema Nacioanal de Atendimento Socioeducativo (SINASE). [...] Em um terceiro ciclo, a análise se foca no processo de construção de uma política municipal em meio aberto [...] que envolve a municipalização das medidas socioeducativas de Liberdade Assistida (L.A) e Prestação de Serviço à Comunidade (PSC). (ALBUQUERQUE, 2015, p. 40 43)

Com a implementação do ECA, diversos avanços foram realizados na garantia da cidadania de crianças e adolescentes; entretanto, os desafios persistem, tendo em vista a manutenção de práticas e discursos do período do Código de Menores, revelando o paradoxo existente sobre as representações sociais deste segmento. Em estudo específico sobre o rearranjo institucional e a eficácia da política de acolhimento institucional de crianças e adolescentes no Brasil, Geralda Miranda analisa que o fortalecimento da proteção social no país avançou, mas o escopo de intervenção estatal ocorre ainda em virtude da pobreza e das condições precárias de vida de muitas crianças e adolescentes:

[...] cabe destacar que, em perspectiva histórica, o acolhimento institucional efetivamente, se tornou uma medida menos recorrente no Brasil do que fora, por exemplo, na década de 1980. Créditos por esse resultado devem ser dados ao fortalecimento do sistema de proteção social, especialmente nas áreas de saúde, assistência social e educação, e ao próprio arranjo institucional do serviço de acolhimento institucional, que estabelece procedimentos para a busca de outras alternativas de proteção da criança e do adolescente em situação de risco. Mas é preciso reconhecer que o perfil de crianças e 
adolescentes que têm sido acolhidos apresenta fortes evidências de que o acolhimento é ainda uma forma de proteção utilizada para as crianças pobres, que correm risco maior de serem vistas como negligenciadas, e deficientes. [...] se houve fortalecimento do sistema de proteção em perspectiva histórica, esse sistema ainda precisa ser aprimorado para oferecer, efetivamente, proteção integral à criança e ao adolescente. (MIRANDA, 2011 p.38-39)

Logo, o escopo de intervenção entre o Brasil colônia - com a roda dos expostos (ou dos enjeitados) ${ }^{9}$ e seus orfanatos - e o período contemporâneo - com o acolhimento institucional - permanece o mesmo: crianças e adolescentes pobres, predominantemente negros, oriundos da periferia urbana.

A herança da infância desvalida persiste, pois existe uma disparidade entre o ordenamento jurídico e o imaginário social, um processo de distinção no trato dessa faixa etária, que conforme Lima (2014):

É possível observar, por exemplo, nos discursos pautados pela mídia, como nas manchetes que estampam alguns jornais a expressão: "Menor mata adolescente". Dando destaque e causando uma cisão dentro da mesma faixa etária em questão. É comum perceber essa distinção no trato dessa faixa etária, contudo ambos são adolescentes. Porém tratados sob o jargão MENOR, aqueles que praticam o ato contra o outro, passam a sofrer um processo de rotulação sobre quem são - fazendo a distinção que existem adolescentes e existem os menores, os primeiros entendidos como normais e os outros, como marginais e infratores, portanto caso de polícia, merecedores de uma intervenção do estado para solução de sua questão. (p. 57)

Na mesma perspectiva e realizando uma reflexão mais ampla, criticando a própria concepção de infância universal no Brasil, Patrice Schuch aduz que a necessidade de produzir políticas específicas para crianças e adolescentes em

${ }^{9}$ (...) aparelho, em geral de madeira, do formato de um cilindro, com um dos lados vazados, assentado num eixo que produzia um movimento rotativo, anexo a um asilo de menores. A utilização desse tipo de engrenagem permitia o ocultamento da identidade daquele(a) que abandonava. (...) A manutenção do segredo sobre a origem social da criança resultava da relação promovida entre abandono de crianças e amores ilícitos. Os espaços especialmente destinados a acolher crianças visavam, num primeiro momento, absorver os frutos de tais uniões. Com o tempo essas instituições passaram a ser utilizadas também por outros motivos (...) Casa dos Expostos, Depósito dos Expostos e casa da Roda eram designações correntes no Brasil para os asilos de menores abandonados (RIZZINI, Apud Gonçalves. In Almeida, 1987, p. 37-38) 
situação de risco e para crianças e adolescentes em situação de conflito com a lei, gera um processo de distinção entre os sujeitos passíveis de proteção e os passíveis de intervenção:

Essa distinção é vista como um avanço em relação à categoria discriminatória do menor, percebido exclusivamente como aquele proveniente das famílias pobres da população brasileira. [...] Considero relevante pensar na hipótese de que essa distinção de políticas vem aumentando consideravelmente o estigma colocado sobre aqueles jovens considerados infratores, isto é, aqueles adolescentes recebedores das medidas socioeducativas, assim como culpabilizando as famílias que recorrem ao abrigamento de seus filhos. Em ambos os processos, o que se torna evidente é que há em paralelo, uma ênfase na infância universa/e uma especialização das políticas e dos aparatos administrativos para o atendimento de personagens menos ambíguos do que o menor. as crianças perigosas e as crianças em perigo. Se, de um lado temos a proposição de uma universalidade da infância, de outro lado temos a reinstalação da desigualdade de sua existência. (SCHUCH, 2005, p. 71)

É de longa data que diversos intelectuais apontam, cada um em sua linhagem de pensamento - que não são estanques nem lineares, as causas de se trilhar a cidadania no Brasil como se tem feito até aqui. Muitas destas análises não podem passar despercebidas de nosso crivo analítico, haja vista que o papel social da infância e juventude no Brasil está engendrado nos processos históricos da nação.

Para Jessé de Souza, a redefinição do negro no Brasil urbano e industrial ocorreu na concepção de que ele, bem como também o dependente ou agregado brasileiro urbano e rural de qualquer cor, foi concebido como imprestável para o exercício de qualquer função na esfera produtiva, constituindo agora um novo quadro de marginalidade. Gera-se assim, um fenômeno de distinção social marcado por um habitus primário, cujo processo histórico de aprendizado coletivo é referência para organização da vida econômica e social moderna:

É precisamente esse processo histórico de aprendizado coletivo que [...] gostaria de denominar de habitus primário, [...] que permite o compartilhamento de uma noção de dignidade efetivamente compartilhada no sentido tayloriano. É essa dignidade, efetivamente compartilhada por 
classes que lograram homogeneizar a economia emocional de todos os seus membros numa medida significativa, que me parece ser o fundamento profundo do reconhecimento social infra e ultra-jurídico, o qual, por sua vez, permite a eficácia social da regra jurídica da igualdade, e, portanto, da noção moderna de cidadania. (SOUZA, 2003, p. 62-63)

Dele, ainda segundo o autor, desdobra-se seu correlato inferior ( habitus precário) e superior (habitus secundário):

O habitus precárioseria o limite do habitus primário para baixo, ou seja, seria aquele tipo de personalidade e de disposições de comportamento que não atendem às demandas objetivas para que, seja um indivíduo, seja um grupo social, possa ser considerado produtivo e útil em uma sociedade de tipo moderno e competitivo, podendo gozar de reconhecimento social com todas as suas dramáticas consequências existenciais e políticas. [...] O que estamos chamando de habitus secundário tem a ver com limite do habitus primário para cima, ou seja, tem a ver com uma fonte de respeito social que pressupõe, no sentido forte do termo, a generalização do habitus primário para amplas camadas da população de uma dada sociedade. (SOUZA, 2003, p. 63-64)

Em outra vertente analítica, mas chegando a resultados muito similares, José Murilo de Carvalho (2008) entende que tal processo ocorre em virtude do surgimento primeiro, no Brasil, dos direitos sociais, emseguida os direitos políticos e civis, das altas taxas de analfabetismo, altos índices de desigualdade social, baixa participação social na vida política, além do Estado ser o principal difusor da cidadania, cujos direitos sociais tiveram significado avanço principalmente em períodos de governos autoritários e populistas, com cerceamento das liberdades políticas e civis.

Em decorrência deste fenômeno histórico, ainda segundo Carvalho, da perspectiva de garantia dos direitos civis, os cidadãos brasileiros podem ser divididos em classes:

Há os de primeira classe, os privilegiados, os doutores, que estão acima da lei, que sempre conseguem defender seus interesses pelo poder do dinheiro e do prestígio social. Os doutores são invariavelmente brancos, ricos, bem vestidos, com formação universitária. São empresários, banqueiros, 
grandes proprietários rurais e urbanos, políticos, profissionais liberais, altos funcionários. Frequentemente, mantêm vínculos importantes nos negócios no governo, no próprio Judiciário. [...] Ao lado dessa elite privilegiada, existe uma grande massa de cidadãos simples, de segunda classe, que estão sujeitos aos rigores e benefícios da lei. São a classe média modesta, os assalariados com carteira de trabalho assinada, os pequeno funcionários, os pequenos proprietários urbanos e rurais. Podem ser brancos, pardos ou negros, têm educação fundamental completa e o segundo grau, em parte ou todo. [...] Frequentemente ficam à mercê da polícia e outros agentes da lei que definem na prática que direitos serão ou não respeitados. Para eles existem os códigos civil e penal, mas aplicados de maneira parcial ou incerta. Finalmente, há os elementos do jargão policial, cidadãos de terceira classe. São a grande população marginal das grandes cidades, trabalhadores urbanos e rurais sem carteira assinada, posseiros, empregadas domésticas, biscateiros, camelôs, menores abandonados (grifo meu), mendigos. São quase invariavelmente pardos ou negros, analfabetos, ou com educação fundamental incompleta. Esses elementos são parte da comunidade política nacional apenas nominalmente. Na prática, ignoram seus direitos civis ou os têm sistematicamente desrespeitados por outros cidadãos, pelo governo, pela polícia. Não se sentem protegidos pela sociedade e pelas leis [...] Para eles vale apenas o Código Penal. (CARVALHO, 2008, p. 215-217)

O menor, enquanto categoria social persiste na sociedade brasileira independente de todo o arcabouço jurídico-administrativo criado e de toda a mudança paradigmática no trato da infância. É como se toda a lógica da cidadania, sua universalidade eseusvalores modernos operassem paralelamenteà estrutura tradicional, patrimonial e escravista da sociedade brasileira. Nos termos de Roberto DaMatta (1997) é a operacionalização da esfera burocrática paralela à esfera moral; na esfera microssocial, é o conflito marcado pela sobreposição da pessoa em detrimento do indivíduo. Sendo assim, a noção de indivíduo é dada como:

[...] realidade concreta, inevitável, independente das ideologias ou representações coletivas e individuais [...] uma unidade social relevante e ativa numa formação social, capaz de gerar os ideais concomitantes de individualismo e igualitarismo, é um fato social histórico, objetivamente dado, 
produto do desenvolvimento de uma formação social específica: a civilização ocidental. (DAMATTA, 1997, p. 221)

E a noção de pessoa, ainda segundo o autor, é definida como...

[...] uma vertente coletiva de individualidade, uma máscara que é colocada em cima do indivíduo ou entidade individualizada (linhagem, clã, família, metade, clube, associação, etc.). Quando a sociedade atribui máscaras a elementos que deseja incorporar no seu bojo, o faz por meio de rituais, penetrando por assim dizer essa coisa que deve ser convertida totalmente em algo significativo. (DAMATTA, 1997, p. 223)

A ideia fundamental de indivíduo (ideologia do individualismo) associada à um conjunto de regras sociais universais, segundo Roberto DaMatta (1987), forjam uma concepção da cidadania como papel social embasado no indivíduo, um dado crítico da sociedade ocidental. Normativamente, o pape/ social de indivíduo le de cidadão) é uma identidade social e de caráter nivelador e igualitário (DAMATTA, 1987, p. 63).

Entretanto, no Brasil, em virtude da hierarquização social o cidadão, universal e igualitário é a todo o momento ameaçado pelos privilégios e exclusivismos das relações pessoais, desenvolve-se assim um modelo de cidadão curioso:

[...] o cidadão brasileiro é o sujeito por excelência das leis impessoais (e universais), bem como o poder brutal da polícia, que servem sistematicamente para diferenciá-lo e explorá-lo impiedosamente, tornando-o um igual para baixo, numa nítida perversão do ideário político liberal[...]. (DAMATTA, 1987, p. 66)

A partir de todos os aportes teóricos apontados, chega-se a um paradoxo de difícil solução. Em primeiro lugar, pois ser criança e adolescente no Brasil é de extrema ambiguidade, cuja sorte de tratamento está fadada principalmente ao estrato social que a mesma ocupa. Ser pré-cidadão, cidadão de segunda classe, subcidadão, confere a estes sujeitos o jargão menor, destinado à marginalidade, vulnerabilidade social, ao poder coercitivo do Estado, invisibilidade social, miséria e toda a sorte de violência. (CARVALHO, 2008; DAMATTA, 1987 e 1997; SANTOS, 1979; SOUZA, 2005) 
Em segundo lugar, o próprio ordenamento jurídico e todo o aparato burocrático-administrativo elaborado na égide da infância universa/para romper com o paradigma da menoridade e, neste sentido, romper com o atraso no que tange o controle social da infância e juventude, serve como meio reprodutor de um habitus precário que hierarquiza e diferencia crianças e adolescentes entre os passiveis de intervenção por serem perigosos (adolescentes infratores) e os passíveis de proteção por serem vulneráveis (crianças e adolescentes cujos direitos foram violados). (SCHUCH, 2005; SOUZA, 2005)

Em terceiro e último lugar, a implementação de um ideal normativo que segue um modelo político-econômico baseado no Welfare State é incompatível com a política econômica neoliberal praticada no Brasil desde a implantação do ECA no anos 1990. As significativas melhoras nos índices de proteção a infância, conforme os estudos de Albuquerque (2015), já citado anteriormente, são oriundas do pequeno ciclo de pujança econômica aliada ao investimento no sistema de proteção social que o Brasil conseguiu alcançar na primeira década deste século. Passado o ciclo de acumulação e adentrado o período de estagnação, vê-se toda a frágil rede proteção social sendo ameaçada.

Os caminhos que a cidadania de crianças e adolescentes percorreu desde o século XIX até os dias atuais são sinuosos, demonstrando avanços e retrocessos na história política do país, marcada por períodos autoritários e democráticos. Os desafios são imensos, pois todo o arranjo social, estatal e econômico reflete a estrutura colonial baseada na monocultura, no latifúndio e na exploração do trabalho (PRADO JR., 1961). No campo da cidadania, os direitos civis são a todo tempo ameaçados em virtude da violência urbana (tema este que merece ampla reflexão, mas que por questões de estrutura textual não foi possível abordar neste trabalho), onde crianças e adolescentes da periferia somam as estatísticas sobre homicídios. (CARVALHO, 2008)

A cidadania de crianças e adolescentes é um tema que merece atenção, pois muitas análises e atores legislações como conquistas que romperam com a doutrina de situação irregulardo Código de Menores de 1927; o que, ao decorrer de nossas reflexões mostra-se como certa ingenuidade ou distorção analítica. Longe de apresentar uma solução, indagamos: qual horizonte de reflexão é possível em nosso país, onde a figura do menor - antes desvalido, abandonado e agora infrator - não conste mais em depoimentos, estatísticas, reportagens e ceda lugar para uma infância universal galgada numa realidade material e não apenas no plano ideológico? 


\section{Referências}

AlBuQUERQUE, Maria do Carmo Alves. O movimento pelos direitos da criança e do adolescente e o controle social sobre a politica socioeducativa: Repertórios de interação societal. Florianópolis, Política \&Sociedade, Vol. 14 $n^{\circ} 29,2015$.

ARANTES, Geraldo Claret de. Estatuto da Criança e do Adolescente: Manual do Operador Juridico. Belo Horizonte: ANAMAGES, 2003.

ARIÉS, Philippe. Hitória Social da Criança e da Família. Rio de Janeiro: Zahar, 1981.

ASSIS, Simone Gonçalves de (Org.) [et al.]. Teoria e prática dos conselhos tutelares e dos conselhos dos direitos da criança e do adolescente. Rio de Janeiro: Editora Fiocruz, 2010.

CARVALHO, José Murilo de. Cidadania no Brasil: um longo caminho. Rio de Janeiro: Civilização Brasileira, 2008.

COELHO, João Gilberto Lucas. A Lei como instrumento. In: A criança, o adolescente, o município: entendendo e implementando a Lei n 8069/1990. Brasília: Unicef, 1990

COSTA, Antônio Carlos Gomes da. O novo Direito da Criança e do Adolescente no Brasil: o Conteúdo e o Processo das Mudanças no Panorama Legal. In: Cadernos do CBIA. Rio de Janeiro, nº 2, 1992.

COSTA, Jurandir Freire. Ordem Médica e Norma Familiar. Rio de Janeiro: Paz e Terra, 1979.

DAMATTA, Roberto. A Casa \& a Rua: Espaço, cidadania, mulher e morte no Brasil. Rio de Janeiro, Rocco, 1997.

Carnavais, malandros e heróis: para uma sociologia do dilema brasileiro. Rio de Janeiro, Zahar, 1987. 
FIGUEROA, Ana Cláudia (org.). Da Situação Irregular às Garantias Processuais da Criança e do Adolescente. São Paulo, FCBIA, 1994.

FOCAULT, Michel. Resumo dos Cursos do Collège de France - 1970-1982. Rio de Janeiro: Jorge Zahar Editora, 1997.

LIBERATI. Adolescente e Ato infracional - medida sócio educativa e pena. São Paulo: Juarez de Oliveira, 2002.

LIMA, Claudinei dos Santos. Os significados do Conselho Tutelar como um dispositivo de governo de crianças e adolescentes. Juiz de Fora: Universidade Federal de Juiz de Fora, 2014.

MENDEZ, Emílio Garcia. Liberdade, Respeito, Dignidade. Brasília, FCBIA, 1991.

MIRANDA, Geralda Luiza de. Arranjos institucionais e eficácia das políticas públicas sociais: o caso do serviço de acolhimento institucional a crianças e adolescentes. S.I.:.S.n.

NABUCO, Joaquim. O Abolicionismo. São Paulo: Publifolha, 2000.

PASSETI, Edson (Org.). Violentados: Crianças, Adolescentes e Justiça. São Paulo, Imaginário, 1995.

PRADO JR, Caio. Formação do Brasil Contemporâneo - Colônia. Brasília: Editora Brasiliense, 6 ${ }^{\mathrm{a}}$ Ed, 1961.

RIZZINI, Irene. "Crianças e Menores - Do Pátrio Poder ao Pátrio Dever. Um Histórico da legislação para a Infância no Brasil". In: Pilotti, F. e Rizzini, I. (Org.). A arte de governar crianças: A história das políticas sociais, da legislação e da assistência à infância no Brasil. Rio de Janeiro: Editora Universitária Santa Úrsula, 1995.

RIZZINI, Irene e Rizzini, Irma. Institucionalização de Crianças no Brasil. Rio de Janeiro, Loyola, 2004. 
SANTOS, Wanderley Guilherme dos. Cidadania e Justiça: A política social na ordem brasileira. Rio de Janeiro: Editora Campos Ltda. 1979.

$\mathrm{SCH} \cup \mathrm{CH}$, Patrice. Práticas de Justiça: Uma etnografia do "Campo de Atenção ao Adolescente Infrator" no Rio Grande do Sul, depois do Estatuto da Criança e do Adolescente. Porto Alegre, 2005. Tese (Doutorado em Antropologia Social) - Programa de Pós Graduação em Antropologia Social, Universidade Federal do Rio Grande do Sul, Porto Alegre, 2005.

SÊDA, Edson. O Novo direito da criança e do adolescente. Rio de Janeiro: Bloch Editores, 1991.

SILVA, Ileizi Fioreli. A sociologia no ensino médio: os desafios instituicionais e epistemológicos para consolidação da disciplina. Natal: Revista Cronos, vol. 8 $n^{\circ} 2,2007$.

SOUZA, Jessé. (Não) Reconhecimento e Subcidadania, ou o que é "Ser Gente"? Disponível em: https://goo.gl/ftNahe. Acesso em: 06 ago. 2017.

VOLPI, Mário (Org.). O adolescente e o ato infracional. São Paulo, Cortez Editora/INESC, 1997.

VOLPI, Mário; SARAIVA, João Batista Costa. Os Adolescentes e a Lei. Para entender o Direito dos Adolescentes, a Prática de Atos Infracionais e Sua Responsabilização. Brasília, ILANUD/Comissão Europeia, 1998. 